\title{
Role of Metabolic Reprogramming in Pulmonary Innate Immunity and Its Impact on Lung Diseases
}

\author{
Charalambos Michaeloudes ${ }^{a}$ Pankaj K. Bhavsar ${ }^{a}$ Sharon Mumby ${ }^{a}$ \\ Bingling $\mathrm{Xu}^{\mathrm{b}}$ Christopher Kim Ming Hui ${ }^{\mathrm{b}}$ Kian Fan Chung ${ }^{\mathrm{a}}$ Ian M. Adcock ${ }^{\mathrm{a}}$ \\ aExperimental Studies and Cell and Molecular Biology, Airway Disease Section, National Heart and Lung Institute, \\ Imperial College London and Biomedical Research Unit, Royal Brompton Hospital, London, UK; ${ }^{b}$ Respiratory and \\ Critical Care Medicine, The University of Hong Kong-Shenzhen Hospital, Shenzhen, China
}

\author{
Keywords \\ Mitochondria · Glycolysis · Biosynthesis · Asthma · Chronic \\ obstructive pulmonary disease
}

\begin{abstract}
Lung innate immunity is the first line of defence against inhaled allergens, pathogens and environmental pollutants. Cellular metabolism plays a key role in innate immunity. Catabolic pathways, including glycolysis and fatty acid oxidation (FAO), are interconnected with biosynthetic and redox pathways. Innate immune cell activation and differentiation trigger extensive metabolic changes that are required to support their function. Pro-inflammatory polarisation of macrophages and activation of dendritic cells, mast cells and neutrophils are associated with increased glycolysis and a shift towards the pentose phosphate pathway and fatty acid synthesis. These changes provide the macromolecules required for proliferation and inflammatory mediator production and reactive oxygen species for anti-microbial effects. Conversely, anti-inflammatory macrophages use primarily FAO and oxidative phosphorylation to ensure efficient energy production and redox balance required for prolonged survival. Deregulation of metabolic reprogram-
\end{abstract}

ming in lung diseases, such as asthma and chronic obstructive pulmonary disease, may contribute to impaired innate immune cell function. Understanding how innate immune cell metabolism is altered in lung disease may lead to identification of new therapeutic targets. This is important as drugs targeting a number of metabolic pathways are already in clinical development for the treatment of other diseases such as cancer.

(c) 2019 The Author(s)

Published by S. Karger AG, Basel

\section{Introduction}

Innate immunity is an evolutionary-conserved and non-antigen-specific defence system that triggers acute inflammatory responses in response to external insults whilst tolerating normal host antigens [1]. In the lungs, infectious agents and inhaled irritants, such as allergens and environmental pollutants, are sensed by the epithelium and antigen-presenting cells that trigger activation of innate effector cells and orchestrate adaptive immune responses to confer prolonged protection [1]. Aberrant inflammatory responses to inhaled insults, and damage 
of the airway epithelium in individuals susceptible to lung disease, promote chronic activation of innate immune effector cells and lead to tissue remodelling in the lungs [2].

Innate immune activation and differentiation are accompanied by widespread changes in cellular metabolism, often described under the umbrella term "metabolic reprogramming" [3]. Deregulation of these metabolic processes can therefore lead to abnormal innate immune function and pathology. In this review, we discuss the current evidence on the role of metabolic reprogramming in the homeostatic and abnormal regulation of innate immune responses, particularly in the context of asthma and chronic obstructive pulmonary disease (COPD), and highlight areas that require further investigation.

\section{Meeting the Metabolic Requirements of Immune Response}

Cellular metabolism consists of interconnected catabolic and anabolic pathways, most of which converge at the mitochondrion. Apart from energy and biosynthetic intermediates, these pathways regulate the balance between reactive oxygen species (ROS) production and anti-oxidant activity and the production of mediators that alter the epigenetic landscape and signal transduction of cells $[4,5]$.

Cells use glucose, fatty acids and amino acids as metabolic substrates to produce the energy required for their function. Catabolism of these substrates leads to the generation of acetyl-co-enzyme A and other intermediates that drive the tricarboxylic acid (TCA) cycle and oxidative phosphorylation (OXPHOS) in the mitochondrion to generate energy in the form of ATP [6]. Catabolic processes are coordinated with biosynthetic pathways that ensure adequate supply of macromolecules and reduced intermediates for the maintenance of redox balance [79]. The cross talk between key catabolic and anabolic metabolic pathways is described in Figure 1.

As cells are exposed to different stimuli, such as proinflammatory cytokines and growth factors, increased biosynthesis and ROS production may need to be prioritised over ATP production, to meet the demands of cell division, inflammatory mediator release or anti-microbial effects. Immune cell activation or differentiation are accompanied by extensive metabolic reprogramming that is integrated into the cell's signalling machinery and is essential for ensuring that cells maintain optimal levels of energy substrates and pre-cursors for the biosynthesis of macromolecules required to support their functions.
Regulation of Cellular Metabolism by Energy and Nutrient Sensors

Cellular metabolism is regulated based on the availability of nutrients and energy, which are sensed by specific signalling mechanisms. AMP-activated protein kinase (AMPK) acts as the main energy sensor of the cell. Under conditions of increased energy demand, an increase in ADP or AMP levels resulting from ATP hydrolysis trigger activation of AMPK, which up-regulates catabolic pathways like glycolysis and fatty acid oxidation (FAO) to produce ATP, whilst inhibiting energy-consuming anabolic pathways like fatty acid and protein synthesis [10-13]. In contrast, increased availability of nutrients, such as amino acids, leads to the activation of mammalian target of rapamycin complex 1 (mTORC1), which promotes mRNA translation and protein synthesis, as well as fatty acid synthesis [14]. mTORC1 also induces glycolysis through a hypoxia-inducible factor (HIF)-1adependent mechanism and activates genes involved in the pentose phosphate pathway (PPP) that generates reduced intermediates for redox regulation and ribose5-phosphate for nucleic acid synthesis [15]. AMPK and mTORC1-mediated pathways are antagonistic, with AMPK inhibiting mTORC1 activity [16]. However, both pathways drive oxidative metabolism by activating peroxisome proliferator-activated receptor-gamma coactivator- $1 \alpha$, a transcriptional co-activator of genes involved in mitochondrial biogenesis and respiration [17, 18].

Inflammatory mediators and growth factors also regulate AMPK and mTOR. AMPK has been shown to be inhibited by the bacterial component lipopolysaccharide (LPS) and stimulated by tumour necrosis factor- $\alpha$, whilst mTOR is activated by transforming growth factor $-\beta$ and other growth factors through phosphatidylinositol 3-kinase (PI3K)/Akt and extracellular signal-regulated kinase-dependent pathways [14, 19]. Moreover, AMPK and mTORC1 also mediate non-metabolic effects, such as regulation of inflammatory responses and cell cycle, and could therefore play a key role in immune responses in the lung $[14,20]$.

\section{Innate Immunity in the Lung}

Inhaled pathogens and noxious particles are sensed by the first line of innate immune defence, which includes the airway epithelium, dendritic cells (DCs) and mast cells, and alveolar macrophages in the distal airways, using pattern recognition receptors (PRRs). These include
Innate Immun 2020;12:31-46 DOI: $10.1159 / 000504344$
Michaeloudes et al. 


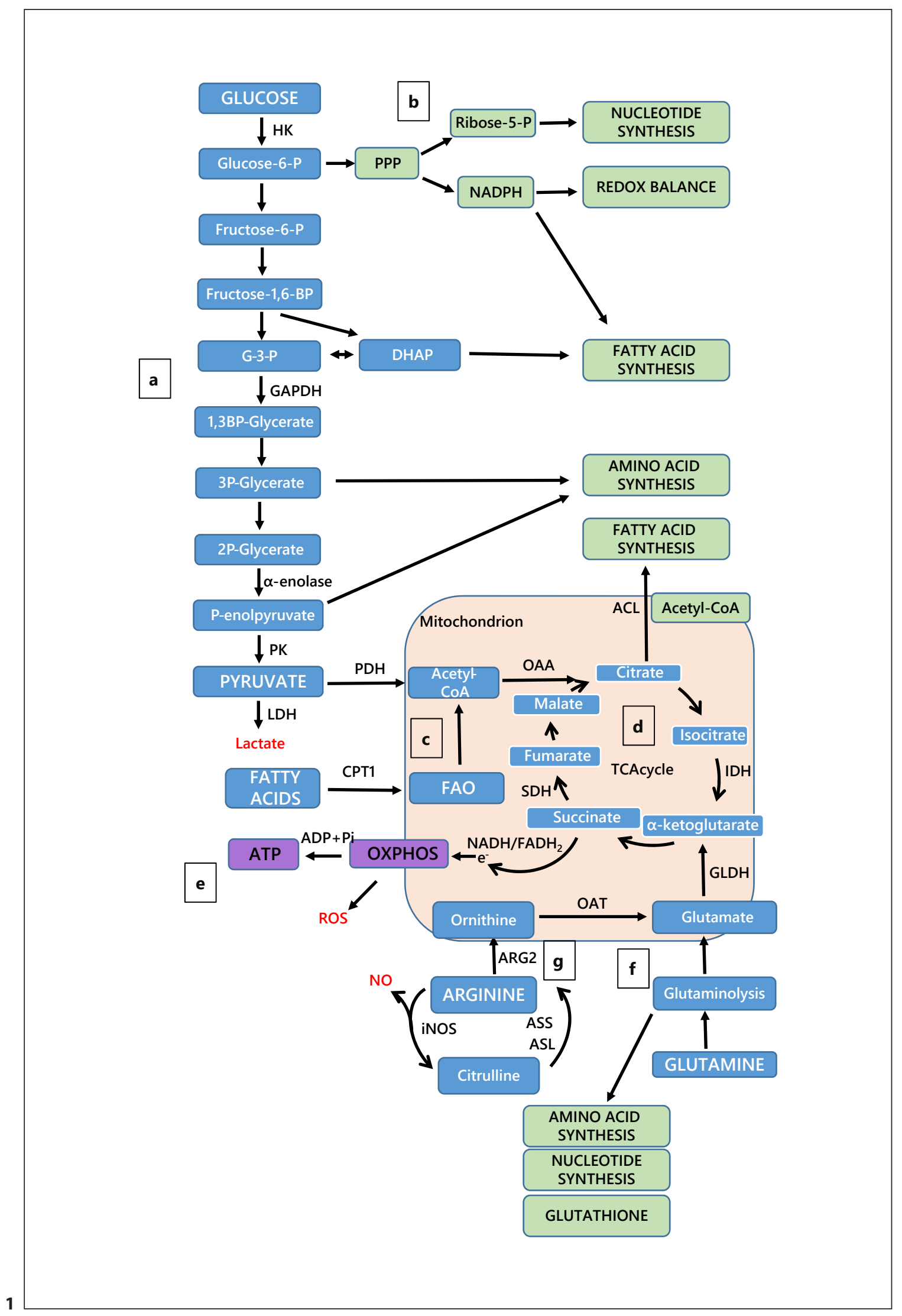

(For legend see next page.) 
Toll-like receptors (TLRs), NOD-like receptors (NLRs) and retinoic acid-inducible gene I-like receptors (RLRs).

The airway epithelium forms a physical barrier comprising of mucous-secreting and ciliated cells, which are involved in the clearance of pathogens and noxious particles, and secretory club cells that produce surfactants and anti-microbial mediators [2]. Cytokines, chemokines, lipid mediators and complement factors released by the epithelium attract and activate effector cells shaping the local immune response [21]. Lung DCs at the basolateral side of the epithelium become activated by inhaled allergens and microbes and migrate to the draining lymph nodes to orchestrate adaptive immune responses [22]. DCs also produce anti-microbial and immunomod- ulatory mediators in response to factors produced by the epithelium and other inflammatory cells [23]. Epithelialderived mediators also activate type 2 innate lymphoid cells (ILC2s), which propagate inflammatory responses through the release of Th2 mediators [24].

The pool of lung macrophages, which consist of alveolar and interstitial macrophages, is believed to primarily develop in the embryo from common progenitors and maintain their numbers through low-level proliferation [25]. Alveolar macrophages reside on the epithelial surface where they scavenge allergens, microbes and pollutants and regulate local immune responses through the release of pro- and anti-inflammatory mediators [26]. Under conditions of inflammation or infection, the num-
Fig. 1. Overview of catabolic and anabolic metabolism in the cell. Catabolic and anabolic metabolic pathways are interconnected and are coordinated depending on the energy demand and nutrient availability of the cell to ensure adequate supply of energy and macromolecules. In this figure, catabolic pathways are shown in blue boxes and pathways involved in the biosynthesis of macromolecules and redox balance are shown in green. a Glucose is taken up by cells through GLUTs and undergoes phosphorylation by HK to Glucose-6-P, which enters the glycolytic pathway in the cytoplasm to produce pyruvate. Under normal aerobic conditions, most of the pyruvate is converted to acetyl-CoA by PDH in the mitochondrion. A proportion of pyruvate is converted to lactate, by LDH. A number of glycolytic intermediates feed into amino acid and fatty acid biosynthesis. b Glucose-6-P can be directed to the PPP that generates Ribose-5-P, a precursor of nucleotide biosynthesis, and NADPH, which is required for the maintenance of redox balance and fatty acid synthesis. c Acetyl-CoA is also produced by FAO in the mitochondrion, following fatty acid conjugation to carnitine by the enzyme CPT1. $\mathbf{d}$ Citrate, produced by the combination of acetyl-CoA and OAA in the mitochondrial matrix, enters the TCA cycle, which generates the reduced intermediates $\mathrm{NADH}$ and $\mathrm{FADH}_{2}$. Citrate can be used in fatty acid biosynthesis through its conversion to acetyl-CoA by ACL. e NADH and $\mathrm{FADH}_{2}$ produced by the TCA cycle carry electrons $\left(\mathrm{e}^{-}\right)$, which are used in the process of OXPHOS to reduce oxygen, leading to the production of energy in the form of ATP through the phosphorylation of ADP. Partial reduction of oxygen during OXPHOS leads to the production of ROS. $\mathbf{f}-\mathbf{g}$ Amino acid catabolism also supports energy production and provides biosynthetic precursors. f Glutamine undergoes glutaminolysis to glutamate, which is converted by GLDH into the TCA cycle intermediate $\alpha$-ketoglutarate. Glutaminolysis also provides glutamate for the synthesis of the antioxidant glutathione and nitrogen for amino acid and nucleotide synthesis. g Arginine is converted to ornithine and urea through the action of the mitochondrial arginase isozyme, ARG2. The enzyme OAT converts ornithine to glutamate, which is then converted to a-ketoglutarate to feed the TCA cycle. Arginine can alternatively be converted to citrulline by induced NO synthase leading to the production of NO. Citrulline is converted back to arginine through the successive actions of the enzymes ASS and ASL. The activation or differentiation of innate immune cells in response to pathogens and inflammatory mediators is associated with changes in the expression and activity of key metabolic enzymes, leading to a shift in the balance between catabolic and anabolic metabolism. These metabolic changes are required to support innate immune function. Increased glycolysis, FAO, OX$\mathrm{PHOS}$, and arginase activity ensure adequate energy production to support prolonged survival, resolution of inflammation and repair in anti-inflammatory cells, such as M2 macrophages. On the other hand, pro-inflammatory macrophages and activated dendritic, mast cells and neutrophils have truncated glycolysis and/or TCA cycle, leading to accumulation of upstream intermediates, which are channelled towards the PPP and anabolic pathways. This results in increased production of proteins, lipids, nucleotides and ROS, which are required for inflammatory mediator production and anti-microbial effects. Abnormal metabolic reprogramming may be a driver of defective innate immune responses in lung diseases, such as asthma and COPD. Fructose-6-P, fructose-6-phosphate; Fructose-1,6-BP, fructose-1,6-biphosphate; G-3-P, glyceraldehyde 3-phosphate; DHAP, dihydroxyacetone phosphate; 1,3BP-Glycerate, 1,3-biphosphoglycerate; 3P-Glycerate, 3-phosphoglycerate; 2P-Glycerate, 2-phosphoglycerate; P-enolpyruvate, phosphoenolpyruvate; $\mathrm{SDH}$, succinate dehydrogenase; $\mathrm{IDH}$, isocitrate dehydrogenase; acetyl-CoA, acetyl-co-enzyme A; LDH, lactate dehydrogenase; CPT1, carnitine palmitoyltransferase 1; GLUT, glucose transporter; $\mathrm{PDH}$, pyruvate dehydrogenase; $\mathrm{HK}$, hexokinase; Glucose-6-P, glucose-6-phosphate; Ribose-5-P, ribose-5-phosphate; OAA, oxaloacetate; NADH, reduced nicotinamide adenine dinucleotide; $\mathrm{FADH}_{2}$, reduced flavin adenine dinucleotide; FAO, fatty acid oxidation; TCA, tricarboxylic acid; ARG2, arginase 2; PPP, pentose phosphate pathway; NADPH, reduced nicotinamide adenine dinucleotide phosphate; PK, pyruvate kinase; OXPHOS, oxidative phosphorylation; ATP, adenosine triphosphate; ADP, adenosine diphosphate; ACL, ATP-citrate lyase; OAT, ornithine aminotransferase; GLDH, glutamate dehydrogenase; ASS, argininosuccinate synthetase; ASL, argininosuccinate lyase; NO, nitric acid; iNOS, induced NO synthase.
Innate Immun 2020;12:31-46 DOI: $10.1159 / 000504344$
Michaeloudes et al. 
bers of alveolar macrophages are replenished by proliferation of the remaining alveolar macrophages and by recruitment of circulating monocytes [25]. Macrophages show a wide range of phenotypes depending on the local environment, with a pro-inflammatory (M1) phenotype on one end and an anti-inflammatory/repair (M2) phenotype on the other end of the spectrum [27, 28]. Proinflammatory macrophages produce higher levels of inflammatory mediators, ROS and nitric oxide (NO) and have microbicidal activity. On the other hand, anti-inflammatory macrophages show increased capacity to clear dead or apoptotic cells by phagocytosis and produce anti-inflammatory cytokines and mediators of tissue repair and remodelling [27].

Mast cells are also found in close proximity to the airway epithelium and, apart from Fce receptors, they express a number of PRRs allowing them to recognise a number of different pathogens and release pro-inflammatory and immunomodulatory mediators [29].

Granulocytes, such as eosinophils and neutrophils, are key effectors of innate immune responses. Eosinophils, which are quiescent in blood under normal conditions, become activated in response to pro-inflammatory mediators and migrate to the lungs where they release an array of mediators and cytotoxic granule proteins causing tissue damage and inflammation [30]. Upon recruitment to the lungs, neutrophils exert their bactericidal action using two main mechanisms: (i) by phagocytosis, which results in bacterial killing through acidification of the phagosome, ROS generated by the respiratory burst and nicotinamide adenine dinucleotide phosphate (NADPH) oxidases, and by anti-microbial peptides and proteins in the phagolysosome; (ii) by trapping and killing bacteria through the formation of neutrophil extracellular traps (NETs) consisting of nuclear DNA and anti-microbial proteins [31].

\section{Asthma}

Asthma is a chronic inflammatory airway disease, which involves extensive remodelling of the airways, due to increased airway smooth muscle mass and fibrosis, as well as mucus hyper-secretion that lead to narrowing of the airway lumen and airflow obstruction. In addition, airway hyper-responsiveness, a key clinical feature of asthma, leads to airway narrowing in response to environmental triggers. Current therapies for asthma, which include corticosteroids and bronchodilators, are effective in controlling symptoms; however, approximately $5 \%$ of

Metabolic Reprogramming and Lung Innate Immunity patients are poorly controlled [32]. New and more effective treatments are therefore required.

It is increasingly recognised that asthma is a heterogeneous disease characterised by different patterns of inflammation. In the majority of patients with asthma, inflammation is driven by an allergen-induced Th2 immune response and eosinophilic inflammation; however, non-atopic patients also develop a similar type of inflammatory response [33]. Importantly, some patients show non-atopic, non-eosinophilic inflammation characterised by airway neutrophilia and associated with more severe and therapy-refractory disease [34]. Understanding the metabolic regulation of innate immune responses in asthma may aid the identification of new therapeutic targets for controlling inflammation and/or biomarkers for disease phenotyping and predicting therapeutic response.

\section{Epithelium}

Disruption of the epithelial barrier by allergen proteases, such as Derp1 in house dust mites and papain, induces Th2-type inflammation through the release of IL33 and thymic stromal lymphopoietin. These cytokines prime DCs and ILC2s to produce eosinophil chemoattractants and Th2 cytokines [35]. Furthermore, increased epithelial permeability due to loss of tight junction integrity and epithelial cell apoptosis permits the infiltration of allergens and infectious agents into the airway wall precipitating the inflammatory response [36].

Studies in animal models of allergen-induced lung inflammation report that ROS and NO-dependent mitochondrial damage and reduced ATP production in the airway epithelium contributes to epithelial cell apoptosis and subsequently airway inflammation $[37,38]$. In patients with asthma, there is evidence of metabolic reprogramming, which may be central to the epithelial-mediated inflammatory responses. A shift in glucose metabolism towards glycolysis, indicated by increased lactate levels, pyruvate kinase (PK) isoform M2 (PKM2) and lactate dehydrogenase A expression, has been reported in airway epithelial cells from patients with asthma and in the lungs of mice exposed to house dust mite. This increase in the use of glycolysis for energy production, which may be a result of NO-mediated suppression of mitochondrial respiration [39], was shown to mediate the allergen-induced expression of IL-33, IL-13 and CCL20 in mouse lungs [40].

An increase in mitochondrial number and enhanced OXPHOS activity, at least partly driven by a reprogramming of arginine metabolism, was also observed in the airway epithelium of patients with asthma [41]. In asth- 
matic epithelial cells, arginine biosynthesis from citrulline is increased, whilst up-regulation of the mitochondrial arginase (ARG) isozyme, ARG 2, drives the conversion of arginine to ornithine. Ornithine can subsequently be transaminated to glutamate, which supplies $\alpha$-ketoglurarate to the TCA cycle (Fig. 1g). Indeed, over-expression of ARG 2 was shown to increase OXPHOS and reduce glycolysis and to inhibit IL-4-induced activation of signal transducer and activator of transcription 6, a driver of Th2 inflammation. Conversely, ARG 2 knock-out mice showed epithelial cells with depolarised mitochondria and increased IL-13 and eotaxin-1 levels and eosinophil numbers in their lungs after ovalbumin challenge [41, 42]. ARG 2 possibly exerts its protective effects by diverting arginine away from $\mathrm{NO}$ synthesis and towards the TCA cycle and OXPHOS, ensuring adequate energy production and a lower glycolytic activity [43]. Arginine is therefore an interesting therapeutic target for restoring the balance between OXPHOS and glycolysis and dampening epithelial-mediated inflammation in asthma.

\section{Dendritic Cells}

Allergens activate the epithelium to secrete chemoattractants of immature DCs, which are recruited to the lungs to acquire and process allergen peptides. DCs are activated by epithelium-derived cytokines and migrate to the lymph nodes to activate naïve $\mathrm{T}$ cells and drive their differentiation into Th2 or Th17 cells depending on the stimulus, co-stimulatory molecules and cytokines present in the local environment [44]. Upon reexposure of an atopic host to allergen, monocyte-derived DCs re-activate Th2 cells to produce IL-5, IL-9 and IL-13 leading to eosinophilia, production of $\operatorname{IgE}$ by $B$ cells and induction of mucus production and airway remodelling. Mast cell activation by antigen-specific IgE leads to release of histamine triggering airway hyperresponsiveness [33].

Studies using murine bone marrow-derived DCs show that the mechanism of DC activation entails increased glycolysis. This serves to support the energetic and biosynthetic demands of activated DCs by providing pyruvate for mitochondrial respiration and channelling intermediates into the PPP to generate NADPH required for redox balance and fatty acid synthesis [45]. Activated DCs maintain a high glycolytic activity and suppressed FAO and OXPHOS through the actions of mTOR and HIF-1 $\alpha$. Activation of Dectin-1, a C-type lectin receptor involved in allergen recognition and airway immune response regulation by lung DCs, was shown to induce a glycolytic shift through an Akt/mTOR/HIF-1a pathway in primary human monocytes exposed to the yeast wall component $\beta$-glucan $[46,47]$. An immediate increase in glycolysis was also observed in response to an array of other stimuli, including bacterial LPS, the yeast component zymosan and the allergen house dust mite. Intriguingly, however, the more pro-inflammatory stimuli, such as LPS and zymosan, also trigger a concurrent inhibition of OXPHOS, whilst house-dust mite-stimulated DCs retain their mitochondrial respiration [48]. These findings suggest that although different stimuli modulate different metabolic pathways, glycolytic activation is always a key early event in DC activation. Inhibition of glycolysis not only attenuates pro-inflammatory mediator production by DCs, but it also reduces their migration to the lymph nodes [48]. Furthermore, ablation of mTOR in mice exposed to house dust mite leads to a metabolic reprogramming of DCs that involves an increase in FAO and causing a switch from Th2 immunity to a Th17-driven neutrophilic response [49]. Glycolysis-fuelled metabolic reprogramming is therefore crucial for the orchestration of adaptive immunity by DCs in allergen-exposed lungs.

\section{Type 2 Innate Lymphoid Cells}

Arginine metabolism and glycolysis are also central to the maturation and activation of ILC2s during allergic responses. HIF-1 1 -driven expression of the glycolytic enzyme PKM2 inhibits IL-33-driven ILC2 maturation by reducing the expression of its receptor IL1RL1 through methylation of its gene ST2. Indeed, mice deficient in the negative regulator of HIF-1 $\alpha$, von Hippel-Lindau protein, show reduced numbers of mature ILC2s and attenuated $\mathrm{Th} 2$ responses in response to intranasal instillation of papain [50]. Furthermore, a study by Monticelli et al. [51], also in papain-exposed mice, shows that arginase 1 (ARG 1) activity supports the ability of ILC2s to proliferate, possibly by providing ornithine for amino acid and polyamine synthesis.

\section{Mast Cells}

IgE-mediated degranulation and histamine release by mast cells during allergic responses also involve changes in the glycolytic pathway $[52,53]$. Fce receptor activation triggers phosphorylation and thus inactivation of PKM2 leading to a truncated glycolysis, which is a crucial step for mast cell degranulation. This is possibly due to accumulation of glycolytic intermediates upstream of pyruvate that acts as precursors for the biosynthesis of lipid mediators released during degranulation (Fig. 1a) [54]. 


\section{Macrophages}

Macrophages play a central role in asthmatic inflammation through the production of cytokines like IL-1 $\beta$, IL- 6 and tumour necrosis factor- $\alpha[55,56]$, whilst there is evidence of decreased phagocytosis in patients with asthma [57]. Polarisation in response to the local microenvironment may contribute to the altered macrophage phenotype observed in asthma. Studies in animal models of asthma suggest a predominance of M2-like macrophages in allergic inflammation and a prevalence of M1-like macrophages in non-allergic inflammation [58]; however, macrophages were shown to respond to microbial challenge and display an M1-like phenotype even after prolonged Th2 stimulation [59]. Interestingly, Girodet et al. [60] have demonstrated that macrophages in the bronchoalveolar lavage fluid of patients with asthma show expression of markers consistent with an M2-like phenotype. Modulating the macrophage phenotype may be an interesting therapeutic intervention; however, the mechanisms controlling polarisation in asthma are incompletely understood.

Studies using murine bone marrow-derived macrophages show that macrophage polarisation is accompanied by distinct metabolic changes that dictate the functional characteristics of each phenotype. These studies have been extensively reviewed by other authors and are not covered in detail in this review [3]. Briefly, M1-like murine macrophages, differentiated by stimulation with LPS and interferon (IFN)- $\gamma$, show a truncated glycolytic pathway that leads to build up of biosynthetic intermediates $[45,61]$ and a defective TCA cycle leads to accumulation of citrate and succinate that are used for fatty acid synthesis $[62,63]$ and pro-inflammatory mediator production $[3,62,64]$. At the same time, inhibition of PPP and induction of induced NO synthase lead to elevated ROS and NO levels required for their bactericidal activity [62]. IL-4-driven M2-like murine macrophages, on the other hand, show more efficient ATP production, required for prolonged survival, through up-regulation of glycolysis, FAO and OXPHOS $[3,65,66]$, and inhibition of energy-consuming biosynthetic pathways [67]. Furthermore, up-regulation of arginase expression contributes to increased ATP production and reduced NO levels in M2-like macrophages [68].

In an allergen-induced mouse model of asthma, increased expression of carnitine palmitoyltransferase 1 (CPT-1) and 3-hydroxyacyl-co-enzyme A dehydrogenase, an enzyme that catalyses the final 3 steps of FAO, was observed predominantly in macrophages of an M2like phenotype (Fig. 1c). Pharmacological inhibition of
CPT-1 and hydroxyacyl-co-enzyme A dehydrogenase using the drugs etoxomir and ranozaline, respectively, reduced the allergen-induced inflammation and airway hyper-responsiveness indicating an important role of FAO in airway allergic inflammation [69]. Nonetheless, other studies show conflicting findings regarding the role of FAO in the differentiation of anti-inflammatory macrophages [3, 70]. Indeed, Divakaruni et al. [71] have demonstrated that FAO is dispensable for M2 polarisation of macrophages and that the inhibitory effect of etoxomir on this process is due to off-target effects.

Although the studies using murine models provide a useful insight into the metabolic regulation of macrophage polarisation, they do not reflect the complex microenvironment of the asthmatic lung. As this includes a multitude of cytokines and chemokines, it is unlikely that these distinct metabolic phenotypes will be seen in humans. Furthermore, human macrophages may have different metabolic requirements and respond differently to inflammatory mediators compared to murine cells. In contrast to the findings in murine macrophages, IL4 -stimulated human monocytes and macrophages were reported to show no change in their glycolytic activity and only a small increase in OXPHOS and FAO [72].

Macrophage metabolism also appears to vary depending on their localisation in the lungs. A study by Lavrich et al. [73] reports that macrophages from induced sputum of healthy subjects rely heavily on glycolysis for energy production, whilst macrophages isolated from bronchoalveolar lavage rely more on OXPHOS. Moreover, findings in a mouse model of LPS-induced lung injury show that the origin of macrophages also determines their metabolic profile. Specifically, resident macrophages exhibit increased TCA cycle and PPP activity associated with increased amino acid biosynthesis and glutathione metabolism, possibly required to maintain their proliferative capacity. On the other hand, recruited macrophages, which are more inflammatory, showed increased glycolysis and arginine metabolism [74]. The suggested association of the metabolic profile of macrophages with their origins and localisation in the respiratory tract adds another layer of complexity to the metabolic profiling of macrophages, suggesting caution when attempting to translate research findings into possible clinical applications.

\section{Eosinophils and Neutrophils}

A number of studies have characterised the metabolic profile of circulating neutrophils and eosinophils, although studies investigating these cells in the lungs, and 
particularly in humans, are scarce. Neutrophils contain few mitochondria and depend primarily on aerobic glycolysis for ATP production; however, both glycolysis and OXPHOS are up-regulated in response to inflammatory stimulation and the induction of phagocytosis $[75,76]$. Porter et al. [77] have reported that human blood eosinophils show a similar glycolytic activity as neutrophils but have a greater number of mitochondria and therefore higher oxygen consumption [78]. Eosinophils also show a more sustained increase in OXPHOS activity and generate greater ROS levels in response to phorbol myristate stimulation compared to neutrophils, suggesting that eosinophils may have a greater metabolic flexibility than neutrophils [77].

Kuo et al. [79] reported an enrichment of the OXPHOS gene signature in the sputum of patients with paucigranulocytic asthma. It is currently unclear whether this metabolic change is driven by macrophages or Tcells; however, this study highlights the significance of the metabolic characterisation of immune cells in identifying asthma endotypes [79].

\section{Chronic Obstructive Pulmonary Disease}

COPD is primarily caused by chronic exposure to inhaled irritants such as cigarette smoke and/or environmental pollutants. The disease is characterised by two types of pathological processes: (i) narrowing of the airways, particularly the small airways, due to extensive remodelling and (ii) destruction of the parenchyma and enlargement of alveoli (emphysema). These pathological changes result from chronic inflammation, particularly in the lung periphery, and often lead to a progressive and irreversible loss of lung function [80].

The inflammatory response in smokers, with or without COPD, involves neutrophilia and increased numbers of alveolar macrophages. Oxidative stress arising from cigarette smoke and/or other inhaled irritants damages the epithelium leading to the release of damage-associated molecular patterns that activate epithelial cells and surface macrophages by binding to PRRs. Activated epithelial cells and macrophages release chemoattractants and cytokines that recruit and activate monocytes and neutrophils, and growth factors such as transforming growth factor- $\beta$, which drive airway remodelling. The recruited inflammatory cells and the epithelium also release proteases, such as matrix metalloproteases, that degrade elastin and cause emphysema [81]. The inflammatory response is more extensive in smokers with COPD and is further amplified in response to acute exacerbations triggered by frequent bacterial and viral infections [82]. Understanding the mechanisms underlying the impaired innate immune defects that lead to susceptibility of COPD patients to exacerbations may lead to new therapies. Changes in cellular metabolism may play a key role in the defective innate immune responses in COPD.

\section{Epithelium}

Aberrant epithelial reprogramming and inflammatory responses drive defective airway innate immune defences in COPD [83]. Oxidative stress-induced mitochondrial dysfunction coupled with impaired autophagic removal of defective mitochondria are thought to lead to a glycolytic shift and augmented mitochondrial ROS in the airway epithelium driving lung inflammation and development of emphysema [84-87]. These studies have been extensively discussed in a previous review [88].

\section{Alveolar Macrophages}

The lungs of COPD patients also show increased numbers of alveolar macrophages with heightened release of inflammatory mediators and proteases, reduced ability to phagocytose apoptotic cells and bacteria and attenuated microbicidal activity, contributing to the inflammatory process and susceptibility to infection [26, $89,90]$. The defective macrophage phenotype in COPD has been associated with impaired metabolic activity. Bewley et al. [91] have shown that alveolar macrophages from healthy subjects have a low baseline mitochondrial ROS production, which is increased in response to pneumococcal challenge to facilitate bacterial killing. In contrast, in COPD macrophages the same study showed elevated baseline mitochondrial ROS production but attenuated induction of mitochondrial ROS in response to challenge leading to impaired intracellular bacterial killing [91]. A study in monocyte-derived macrophages, on the other hand, reported no differences in baseline mitochondrial ROS between healthy and COPD cells but showed an augmented induction of mitochondrial ROS associated with impaired phagocytosis in response to bacterial challenge [92]. These studies indicate inherent mitochondrial impairment in COPD macrophages, possibly caused by prolonged exposure to oxidative stress. This dysfunction may promote pro-inflammatory mediator release through mitochondrial ROS production and an adaptive up-regulation of glycolysis [93]. Moreover, these findings highlight a difference in the regulation of metabolic activity in response to bacterial challenge between macrophages of different origins suggest-
38

Innate Immun 2020;12:31-46 DOI: $10.1159 / 000504344$
Michaeloudes et al. 
ing that more detailed work will be required to understand the metabolic changes associated with defective macrophage function in COPD.

\section{Neutrophils}

The lungs of patients with COPD are infiltrated by neutrophils with enhanced respiratory burst and increased speed of migration, but with a lack of migratory accuracy, increasing their potential to inflict damage [94]. Increased NET production by neutrophils in COPD has also been associated with disease progression and the development of autoimmunity as a result of the increased levels of self-DNA contained in the NETs $[95,96]$. Neutrophils rely mainly on glycolysis for their energy needs and for the production of intermediates that feed into the PPP to generate NADPH, which is used by NADPH oxidases for the generation of ROS required for bacterial killing and for the induction of NET formation $[97,98]$. Despite the predominance of glycolysis as a source of energy in neutrophils, their few mitochondria maintain their membrane potential and contribute to the localised production of ATP and ROS required for the coordination of neutrophil migration [99, 100]. Mitochondrial-derived ROS also induces NET formation by neutrophils playing a central role in the development of autoimmunity [101]. Impaired mitochondrial function and altered glucose metabolism may therefore lead to defective neutrophil migration and function in COPD. Studies into the metabolic regulation of neutrophil function in COPD would therefore be crucial.

\section{Respiratory Tract Infections}

Viral and bacterial infections are major causes of disease exacerbations in patients with asthma and COPD and are associated with worsening of symptoms, rapid decline in lung function and increased mortality [102].

The main types of viruses causing airway disease, human rhinovirus, respiratory syncytial virus and influenza A virus are recognised by the innate immune system through PRRs. During viral infection, the viral membrane and capsid are degraded in acidified endosomes, releasing the single-stranded RNA, which is detected by TLR7. Apoptotic, virus-infected cells are phagocytosed by macrophages, and double-stranded RNA is detected by TLR3. TLRs trigger an acute response that involves production of type I IFNs, which activate anti-viral responses in neighbouring cells, and pro-inflammatory cytokines that recruit effector cells, including neutrophils,

Metabolic Reprogramming and Lung Innate Immunity monocytes and natural killer cells, to the site of infection [103-105]. Viral RNA in the cytoplasm of infected cells is recognised by retinoic acid-inducible gene I, which induces the expression of IFN and pro-inflammatory cytokines $[2,105]$. Viral infection also stimulates the formation of the NOD-, LRR- and pyrin domain-containing 3 (NLRP3) inflammasome, which mediates the release of active IL- $1 \beta$ and IL-18 through caspase 1-mediated cleavage [105].

A retrospective study of positron emission tomography scans of patients with influenza infection showed increase glucose uptake in their lungs [106]. Indeed, influenza virus triggers elevated glucose uptake and metabolism associated with the activation of glutaminolysis in bronchial epithelial cells. Similarly, plasmacytoid DCs from healthy human subjects show increased glycolytic activity after intranasal administration of live attenuated influenza vaccine [107]. These metabolic changes are triggered by viral recognition through TLRs and a subsequent up-regulation of the transcription factor c-myc in response to infection of the host cell $[106,107]$. Rhinoviral infection of primary human fibroblasts and HeLa cells induces glucose uptake within $1.5 \mathrm{~h}$ through PI3K-dependent up-regulation of glucose transporter-1 expression and increases glucose availability by activating glycogenolysis. This early glycolytic response drives an anabolic state in the host cells that entails enhanced nucleotide biosynthesis and lipogenesis, which are essential for viral replication [108]. In addition, glutaminolysis is important as a source of carbon and nitrogen required to meet the biosynthetic requirements of viral replication [109]. Glycolysis also promotes the acidification of endosomes, which is required for the uncoating of viral particles and the release of viral ribonucleoproteins into the cytoplasm during viral replication $[110,111]$

A recent study by Mallia et al. [112] reported elevated glucose levels in the sputum of patients with COPD, which further increased in response to exacerbations or experimental infection with rhinovirus. Sputum samples with higher glucose concentrations sustained a greater bacterial growth, suggesting that increased airway glucose in response to viral infection may promote secondary bacterial infections [112]. Changes in metabolism, particularly glucose metabolism, may therefore encourage viral and bacterial infections and could therefore be targeted therapeutically.

However, metabolic reprogramming is also central in the homeostatic response to viral infection, thus targeting them could have detrimental effects. Mitochondria are essential for the induction of anti-viral responses by 
RLRs. Upon recognition of cytoplasmic viral RNA, RLRs interact with and activate the adaptor protein mitochondrial anti-viral signalling proteins (MAVS) located on the mitochondrial outer membrane through their caspaserecruitment domains. MAVS activation drives pro-in- flammatory cytokine expression through nuclear factor$\kappa \mathrm{B}$ activation and type I IFN expression through IFN regulatory factor activation $[113,114]$. The anti-viral function of MAVS requires normal mitochondrial respiration, and attenuated OXPHOS or mtDNA mutations were shown

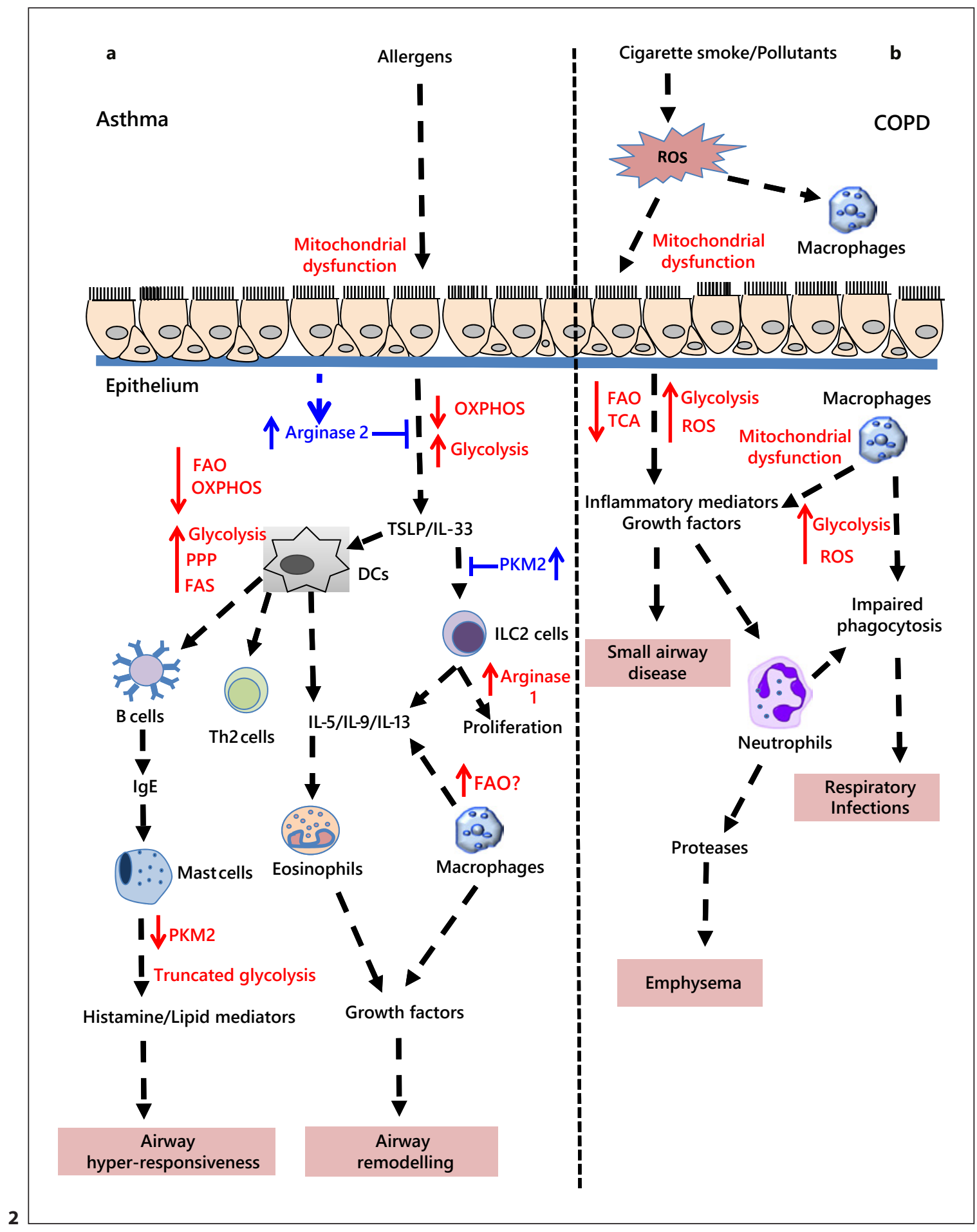

(For legend see next page.) 
to cause impaired RLR-mediated anti-viral responses and susceptibility to influenza infection [115]. Glycolytic activity also mediates IFN- $\alpha$ release and the expression of co-stimulatory molecules in human DCs exposed to influenza virus [107].

\section{NLRP3 Inflammasome}

The NLRP3 inflammasome is an important host defence mechanism activated by pathogens, cellular damage and stress. Persistent NLRP3 inflammasome activation is thought to be involved in abnormal innate immune responses in asthma and COPD [116]. The NLRP3 inflammasome is regulated by metabolic signals, specifically by glycolysis-dependent mitochondrial ROS and saturated fatty acids [117-119]. Indeed, 2-deoxy-D-glucose, a compound that inhibits hexokinase, the first step of the glycolytic pathway, attenuated NRLP3 activation and IL-1 $\beta$ and IL-18 production in a mouse model of LPS-induced acute lung injury [120]. Furthermore, mitochondrial damage caused by allergens or the environmental pollutant ozone in mouse lungs promotes airway inflammation and remodelling through ROS-mediated activation of the NLRP3 inflammasome [121, 122]. These findings suggest that metabolic perturbations may contribute to aberrant activation of NLRP3 inflammasome in asthma and COPD.

Fig. 2. Metabolic changes associated with innate immune responses in lung disease. An overview of the metabolic changes associated with innate immune cell regulation in asthma (a) and COPD (b). a Studies in animal models show that chronic exposure to inhaled allergen leads to mitochondrial dysfunction in the airway epithelium that is accompanied by a reduction in OXPHOS and activation of glycolysis, which supports the production of cytokines and inflammatory cell recruitment. Bronchial epithelial cells from patients with asthma also show increased glycolysis, but at the same time exhibit up-regulation of ARG 2, which acts as a protective mechanism by restoring OXPHOS, reducing glycolysis and inhibiting inflammatory mediator production. Epithelial-derived IL-33 and TSLP induce the maturation and activation of dendritic and ILC2 that orchestrate adaptive immune responses. Upon activation, DCs show a reduction in FAO and OXPHOS and an upregulation of glycolysis, PPP and FAS to meet the biosynthetic demands of inflammatory mediator production. IL-33-induced ILC2 maturation, on the other hand, is inhibited by PKM2 through a reduction in the expression of the IL-33 receptor, IL1RL1. Moreover, up-regulation of ARG 1 supports allergen-dependent proliferation of ILC2 cells. IgE produced by B cells activates mast cells to release histamine and lipid mediators driving airway inflammation and hyper-responsiveness. Binding of IgE to its receptor trig-

\section{Therapeutic Approaches}

Current evidence highlights a number of metabolic pathways that may play an integral role in innate immune responses in asthma and COPD; these are summarised in Figure 2. Restoration of normal metabolic function by targeting critical metabolic enzymes or sensors may offer new therapeutic opportunities for innate immune dysfunction in lung disease.

Activation of glycolysis (Fig. 1a), often associated with a reduction in OXPHOS and a shift towards biosynthetic pathways, is an early step in the maturation, migration, differentiation and pro-inflammatory activation of innate immune cells and is therefore an attractive therapeutic target for chronic inflammatory lung diseases. Dimethyl fumarate, an immunomodulatory drug used for multiple sclerosis and psoriasis treatment, was recently shown to inhibit glycolysis by inactivating glyceraldehyde 3-phosphate dehydrogenase, causing an increase in OXPHOS and M2 polarisation of macrophages [123]. Furthermore, dichloroacetic acid, a drug that attenuates the activity of pyruvate dehydrogenase kinase, a negative regulator of pyruvate dehydrogenase, restricts glycolysis and enhances OXPHOS by increasing the flow of pyruvate into the mitochondrion. Dichloroacetic acid has clinical efficacy in pulmonary hypertension where metabolic reprogramming also occurs [124]. Truncated glycolysis due to inactivation of PKM2 leads to channelling of upstream

gers inactivation of PKM2, truncating glycolysis and leading to accumulation of upstream intermediates that are channelled to the biosynthesis of lipid mediators released during degranulation. Studies in animal models report a role of FAO in M2 differentiation of macrophages and the development of allergic inflammation; however, other studies show conflicting findings. b Cigarette smoke and other inhaled pollutants are thought to induce ROSmediated mitochondrial dysfunction and attenuated energy production, due to impaired FAO and TCA, in the epithelium of patients with COPD. These defects may be accompanied by increased glycolysis and ROS production that drive epithelial-mediated inflammatory cell recruitment and lung pathology. Mitochondrial dysfunction in peripheral and alveolar macrophages from patients with COPD has also been associated with mitochondrial ROS production and increased glycolysis, which possibly lead to increased inflammatory mediator production and defective phagocytosis and bactericidal activity. TSLP, thymic stromal lymphopoietin; OXPHOS, oxidative phosphorylation; ARG 1, arginase 1; ARG 2, arginase 2; ILC2, type 2 innate lymphoid cells; DC, dendritic cells; FAO, fatty acid oxidation; PPP, pentose phosphate pathway; FAS, fatty acid synthesis; PKM2, pyruvate kinase isoform M2; ROS, reactive oxygen species; TCA, tricarboxylic acid; COPD, chronic obstructive pulmonary disease. 
glycolytic intermediates towards the biosynthesis of macromolecules required for the activation of immune cells such as macrophages and mast cells. A number of PKM2 activators are currently in preclinical development, and dimethylaminomicheliolide, a natural product-derived small molecule, has entered clinical trials for leukaemia treatment [125]. Targeting upstream drivers, such as mTORC1, may be another way of inhibiting the metabolic shift towards glycolysis and anabolic metabolism in immune cells. Several rapamycin analogues (rapalogs) are in clinical development for cancer, however, with limited clinical success [126].

The protective effect of increased arginine flux through the mitochondrial ARG 2 in asthmatic epithelial cells suggests a possible benefit of inducing ARG 2 activity in the lungs (Fig. 1g). However, as increased arginase activity in the airways contributes to hyper-responsiveness and the development of remodelling, there is increasing interest in arginase inhibitors as potential therapies for lung disease. Indeed, pulmonary delivery of an arginase inhibitor attenuates lung pathology in animal models of disease [127-129].

FAO (Fig. 1c) is thought to play a role in M2-like macrophage differentiation and allergic inflammation in animal models, highlighting inhibitors of fatty acid uptake or oxidation as potential treatments. The CPT-1 inhibitor perhexiline and the FAO inhibitors trimetazidine and ranolazine are licenced for the treatment of heart disease [130].

Excessive mitochondrial ROS, resulting from mitochondrial dysfunction, has been associated with impaired phagocytosis in COPD macrophages as well as in the activation of the NRLP3 inflammasome. The mitochondrial-targeted anti-oxidant MitoQ has shown promising results in preclinical studies of lung disease and showed safety in clinical trials for Parkinson's and hepatitis C-induced liver disease [131-133]. Furthermore, the diabetes drug metformin that exerts anti-inflammatory effects, partly through inhibiting ROS production at the mitochondrial complex I, has shown limited effect on systemic inflammation and clinical end points in a COPD trial [134].

A number of drugs targeting different aspects of cellular metabolism are already in clinical development for the treatment of other diseases [135]. Caution is required, however, when targeting metabolic pathways as inhibition of these pathways may also have detrimental effects by affecting normal lung immune responses by restricting the cells' energy production, biosynthetic capacity and ROS production, and thus compromising their activation in response to inhaled insults.

\section{Outlook}

In recent years, there has been great progress in understanding immunometabolism, particularly with respect to the innate immune system. A number of studies, predominantly using animal models, have shown that metabolic reprogramming is an integral part of the homeostatic regulation of innate immunity. As animal studies cannot fully reflect the human in vivo environment, it is now essential to better understand how metabolism is deregulated in immune cells from patients with lung disease, as this will allow the identification of new biomarkers for disease endotyping as well as therapeutic targets. This is particularly important, as a number of metabolic pathways are "druggable" and inhibitors are already in clinical development for the treatment of diseases like cancer and pulmonary hypertension.

\section{Statement of Ethics}

The authors have no ethical conflicts to disclose.

\section{Disclosure Statement}

The authors have no conflicts of interest to declare.

\section{Funding Sources}

This work was funded by the Sanming Project of Medicine in Shenzhen (SZSM201612096) and the Dunhill Medical Trust (R368/0714).

\section{Author Contributions}

C.M. contributed to the conception of the review and wrote the first draft of the manuscript. P.K.B., S.M., B.X., and C.K.H. contributed to the writing of the first draft of the manuscript. K.F.C. and I.M.A. contributed to the conception of the review, provided a critical review of the manuscript and approved the final draft.

\footnotetext{
References

1 Iwasaki A, Medzhitov R. Control of adaptive immunity by the innate immune system. Nat Immunol. 2015 Apr;16(4):343-53.

2 Hiemstra PS, McCray PB Jr, Bals R. The innate immune function of airway epithelial cells in inflammatory lung disease. Eur Respir J. 2015 Apr;45(4):1150-62.

3 Van den Bossche J, O'Neill LA, Menon D. Macrophage Immunometabolism: Where Are We (Going)? Trends Immunol. 2017 Jun; 38(6):395-406
}

J Innate Immun 2020;12:31-46 DOI: $10.1159 / 000504344$
Michaeloudes et al. 
4 Vander Heiden MG, Cantley LC, Thompson CB. Understanding the Warburg effect: the metabolic requirements of cell proliferation. Science. 2009 May;324(5930):1029-33.

5 Wilson DF. Regulation of cellular metabolism: programming and maintaining metabolic homeostasis. J Appl Physiol (1985). 2013 Dec;115(11):1583-8.

6 Mori M. Regulation of nitric oxide synthesis and apoptosis by arginase and arginine recycling. J Nutr. 2007 Jun;137(6 Suppl 2):1616S20S.

7 Metallo CM, Gameiro PA, Bell EL, Mattaini KR, Yang J, Hiller K, et al. Reductive glutamine metabolism by IDH1 mediates lipogenesis under hypoxia. Nature. 2011 Nov; 481(7381):380-4.

8 Hensley CT, Wasti AT, DeBerardinis RJ. Glutamine and cancer: cell biology, physiology, and clinical opportunities. J Clin Invest. 2013 Sep;123(9):3678-84.

9 Jiang P, Du W, Wu M. Regulation of the pentose phosphate pathway in cancer. Protein Cell. 2014;5(8):592-602.

10 Li Y, Xu S, Mihaylova MM, Zheng B, Hou X, Jiang $B$, et al. AMPK phosphorylates and inhibits SREBP activity to attenuate hepatic steatosis and atherosclerosis in diet-induced insulin-resistant mice. Cell Metab. 2011 Apr; 13(4):376-88

11 Merrill GF, Kurth EJ, Hardie DG, Winder WW. AICA riboside increases AMP-activated protein kinase, fatty acid oxidation, and glucose uptake in rat muscle. Am J Physiol. 1997 Dec;273(6):E1107-12.

12 Kurth-Kraczek EJ, Hirshman MF, Goodyear LJ, Winder WW. $5^{\prime}$ AMP-activated protein kinase activation causes GLUT4 translocation in skeletal muscle. Diabetes. 1999 Aug;48(8): 1667-71.

13 Hardie DG. AMP-activated protein kinase: a cellular energy sensor with a key role in metabolic disorders and in cancer. Biochem Soc Trans. 2011 Jan;39(1):1-13.

14 Yuan HX, Xiong Y, Guan KL. Nutrient sensing, metabolism, and cell growth control. Mol Cell. 2013 Feb;49(3):379-87.

15 Düvel K, Yecies JL, Menon S, Raman P, Lipovsky AI, Souza AL, et al. Activation of a metabolic gene regulatory network downstream of mTOR complex 1. Mol Cell. 2010 Jul;39(2):171-83.

16 Gwinn DM, Shackelford DB, Egan DF, Mihaylova MM, Mery A, Vasquez DS, et al. AMPK phosphorylation of raptor mediates a metabolic checkpoint. Mol Cell. 2008 Apr; 30(2):214-26.

17 Jäger S, Handschin C, St-Pierre J, Spiegelman BM. AMP-activated protein kinase (AMPK) action in skeletal muscle via direct phosphorylation of PGC-1alpha. Proc Natl Acad Sci USA. 2007 Jul;104(29):12017-22.

18 Cunningham JT, Rodgers JT, Arlow DH, Vazquez F, Mootha VK, Puigserver P. mTOR controls mitochondrial oxidative function through a YY1-PGC-1alpha transcriptional complex. Nature. 2007 Nov;450(7170):736-40.
19 Wu XL, Wang LK, Yang DD, Qu M, Yang YJ, Guo F, et al. Effects of Glut1 gene silencing on proliferation, differentiation, and apoptosis of colorectal cancer cells by targeting the TGF- $\beta$ / PI3K-AKT-mTOR signaling pathway. J Cell Biochem. 2018 Feb;119(2):2356-67.

20 Mancini SJ, White AD, Bijland S, Rutherford C, Graham D, Richter EA, et al. Activation of AMP-activated protein kinase rapidly suppresses multiple pro-inflammatory pathways in adipocytes including IL-1 receptor-associated kinase-4 phosphorylation. Mol Cell Endocrinol. 2017 Jan;440:44-56.

21 Hartl D, Tirouvanziam R, Laval J, Greene $\mathrm{CM}$, Habiel D, Sharma L, et al. Innate Immunity of the Lung: From Basic Mechanisms to Translational Medicine. J Innate Immun. 2018;10(5-6):487-501.

22 von Garnier C, Filgueira L, Wikstrom M, Smith M, Thomas JA, Strickland DH, et al. Anatomical location determines the distribution and function of dendritic cells and other APCs in the respiratory tract. J Immunol. 2005 Aug; 175(3):1609-18.

23 Hammad H, Lambrecht BN. Recent progress in the biology of airway dendritic cells and implications for understanding the regulation of asthmatic inflammation. J Allergy Clin Immunol. 2006 Aug;118(2):331-6.

24 McKenzie AN. Type-2 innate lymphoid cells in asthma and allergy. Ann Am Thorac Soc. 2014 Dec;11 Suppl 5:S263-70.

25 Garbi N, Lambrecht BN. Location, function, and ontogeny of pulmonary macrophages during the steady state. Pflugers Arch. 2017 Apr;469(3-4):561-72.

26 Belchamber KB, Donnelly LE. Macrophage Dysfunction in Respiratory Disease. Results Probl Cell Differ. 2017;62:299-313.

27 Arora S, Dev K, Agarwal B, Das P, Syed MA. Macrophages: their role, activation and polarization in pulmonary diseases. Immunobiology. 2018 Apr - May;223(4-5):383-96.

28 Murray PJ, Allen JE, Biswas SK, Fisher EA, Gilroy DW, Goerdt S, et al. Macrophage activation and polarization: nomenclature and experimental guidelines. Immunity. $2014 \mathrm{Jul}$; 41(1):14-20.

29 St John AL, Abraham SN. Innate immunity and its regulation by mast cells. J Immunol. 2013 May; 190(9):4458-63.

30 Tashkin DP, Wechsler ME. Role of eosinophils in airway inflammation of chronic obstructive pulmonary disease. Int J Chron Obstruct Pulmon Dis. 2018 Jan;13:335-49.

31 Meijer M, Rijkers GT, van Overveld FJ. Neutrophils and emerging targets for treatment in chronic obstructive pulmonary disease. Expert Rev Clin Immunol. 2013 Nov;9(11): 1055-68.

32 Chung KF. New treatments for severe treatment-resistant asthma: targeting the right patient. Lancet Respir Med. 2013 Oct;1(8):63952.

33 Barnes PJ. Targeting cytokines to treat asthma and chronic obstructive pulmonary disease. Nat Rev Immunol. 2018 Jul;18(7):454-66.
34 Green RH, Brightling CE, Woltmann G, Parker D, Wardlaw AJ, Pavord ID. Analysis of induced sputum in adults with asthma: identification of subgroup with isolated sputum neutrophilia and poor response to inhaled corticosteroids. Thorax. 2002 Oct;57(10):875-9.

35 Iijima K, Kobayashi T, Hara K, Kephart GM, Ziegler SF, McKenzie AN, et al. IL-33 and thymic stromal lymphopoietin mediate immune pathology in response to chronic airborne allergen exposure. J Immunol. 2014 Aug; 193(4):1549-59.

36 Holgate ST. Pathogenesis of asthma. Clin Exp Allergy. 2008 Jun;38(6):872-97.

37 Mabalirajan U, Dinda AK, Kumar S, Roshan R, Gupta P, Sharma SK, et al. Mitochondrial structural changes and dysfunction are associated with experimental allergic asthma. J Immunol. 2008 Sep;181(5):3540-8.

38 Aguilera-Aguirre L, Bacsi A, Saavedra-Molina A, Kurosky A, Sur S, Boldogh I. Mitochondrial dysfunction increases allergic airway inflammation. J Immunol. 2009 Oct;183(8):5379-87.

39 Ozawa S, Ueda S, Imamura H, Mori K, Asanuma K, Yanagita M, et al. Glycolysis, but not Mitochondria, responsible for intracellular ATP distribution in cortical area of podocytes. Sci Rep. 2015 Dec;5(1):18575.

40 Qian X, Aboushousha R, van de Wetering C, Chia SB, Amiel E, Schneider RW, et al. IL-1/ inhibitory kappaB kinase $\varepsilon$-induced glycolysis augment epithelial effector function and promote allergic airways disease. J Allergy Clin Immunol. 2018;142(2):435-50.e10.

$41 \mathrm{Xu} \mathrm{W}$, Ghosh S, Comhair SA, Asosingh K, Janocha AJ, Mavrakis DA, et al. Increased mitochondrial arginine metabolism supports bioenergetics in asthma. J Clin Invest. 2016 Jul;126(7):2465-81.

$42 \mathrm{Xu} \mathrm{W}$, Comhair SA, Janocha AJ, Lara A, Mavrakis LA, Bennett CD, et al. Arginine metabolic endotypes related to asthma severity. PLoS One. 2017 Aug;12(8):e0183066.

43 Yamamoto M, Tochino Y, Chibana K, Trudeau JB, Holguin F, Wenzel SE. Nitric oxide and related enzymes in asthma: relation to severity, enzyme function and inflammation. Clin Exp Allergy. 2012 May;42(5):760-8.

44 Hammad H, Lambrecht BN. Barrier Epithelial Cells and the Control of Type 2 Immunity. Immunity. 2015 Jul;43(1):29-40.

45 Everts B, Amiel E, Huang SC, Smith AM, Chang $\mathrm{CH}$, Lam WY, et al. TLR-driven early glycolytic reprogramming via the kinases TBK1-IKKУ supports the anabolic demands of dendritic cell activation. Nat Immunol. 2014 Apr;15(4):323-32.

46 Cheng SC, Quintin J, Cramer RA, Shepardson KM, Saeed S, Kumar V, et al. mTOR- and HIF-1 $\alpha$-mediated aerobic glycolysis as metabolic basis for trained immunity. Science. 2014 Sep;345(6204):1250684.

47 Fukahori S, Matsuse H, Tsuchida T, Kawano T, Tomari S, Fukushima C, et al. Aspergillus fumigatus regulates mite allergen-pulsed dendritic cells in the development of asthma. Clin Exp Allergy. 2010 Oct;40(10):1507-15. 
48 Guak H, Al Habyan S, Ma EH, Aldossary H, Al-Masri M, Won SY, et al. Glycolytic metabolism is essential for CCR7 oligomerization and dendritic cell migration. Nat Commun. 2018 Jun;9(1):2463.

49 Sinclair C, Bommakanti G, Gardinassi L, Loebbermann J, Johnson MJ, Hakimpour P, et al. mTOR regulates metabolic adaptation of APCs in the lung and controls the outcome of allergic inflammation. Science. 2017 Sep; 357(6355):1014-21.

50 Li Q, Li D, Zhang X, Wan Q, Zhang W, Zheng M, et al. E3 Ligase VHL Promotes Group 2 Innate Lymphoid Cell Maturation and Function via Glycolysis Inhibition and Induction of Interleukin-33 Receptor. Immunity. 2018; 48(2):258-70.e5.

51 Monticelli LA, Buck MD, Flamar AL, Saenz SA, Tait Wojno ED, Yudanin NA, et al. Arginase 1 is an innate lymphoid-cell-intrinsic metabolic checkpoint controlling type 2 inflammation. Nat Immunol. 2016 Jun; 17(6): 656-65.

52 Kitahata Y, Nunomura S, Terui T, Ra C. Prolonged culture of mast cells with high-glucose medium enhances the Fc epsilon RI-mediated degranulation response and leukotriene $\mathrm{C} 4$ production. Int Arch Allergy Immunol. 2010; 152 Suppl 1:22-31.

53 Chakravarty N. Further observations on the inhibition of histamine release by 2-deoxyglucose. Acta Physiol Scand. 1968 Apr;72(4): $425-32$.

54 Ryu H, Walker JK, Kim S, Koo N, Barak LS, Noguchi T, et al. Regulation of M2-type pyruvate kinase mediated by the high-affinity $\operatorname{IgE}$ receptors is required for mast cell degranulation. Br J Pharmacol. 2008 Jul;154(5):103546.

55 Tang C, Rolland JM, Ward C, Thien F, Li X, Gollant S, et al. Differential regulation of allergen-specific $\mathrm{T}(\mathrm{H} 2)$ - but not $\mathrm{T}(\mathrm{H} 1)$-type responses by alveolar macrophages in atopic asthma. J Allergy Clin Immunol. 1998 Sep; 102(3):368-75.

56 Herbert C, Scott MM, Scruton KH, Keogh RP, Yuan KC, Hsu K, et al. Alveolar macrophages stimulate enhanced cytokine production by pulmonary CD4+ T-lymphocytes in an exacerbation of murine chronic asthma. Am J Pathol. 2010 Oct;177(4): 1657-64.

57 Liang Z, Zhang Q, Thomas CM, Chana KK, Gibeon D, Barnes PJ, et al. Impaired macrophage phagocytosis of bacteria in severe asthma. Respir Res. 2014 Jun;15(1):72.

58 Robbe P, Draijer C, Borg TR, Luinge M, Timens W, Wouters IM, et al. Distinct macrophage phenotypes in allergic and nonallergic lung inflammation. Am J Physiol Lung Cell Mol Physiol. 2015 Feb;308(4):L358-67.

59 Varin A, Mukhopadhyay S, Herbein G, Gordon S. Alternative activation of macrophages by IL- 4 impairs phagocytosis of pathogens but potentiates microbial-induced signalling and cytokine secretion. Blood. 2010 Jan; 115(2):353-62.
60 Girodet PO, Nguyen D, Mancini JD, Hundal $\mathrm{M}$, Zhou X, Israel E, et al. Alternative Macrophage Activation Is Increased in Asthma. Am J Respir Cell Mol Biol. 2016 Oct;55(4):467-75.

61 Palsson-McDermott EM, Curtis AM, Goel G, Lauterbach MA, Sheedy FJ, Gleeson LE, et al. Pyruvate Kinase M2 Regulates Hif-1 $1 \alpha$ Activity and IL- $1 \beta$ Induction and Is a Critical Determinant of the Warburg Effect in LPS-Activated Macrophages. Cell Metab. 2015 Feb; 21(2):347.

62 Jha AK, Huang SC, Sergushichev A, Lampropoulou V, Ivanova $\mathrm{Y}$, Loginicheva $\mathrm{E}$, et al. Network integration of parallel metabolic and transcriptional data reveals metabolic modules that regulate macrophage polarization. Immunity. 2015 Mar;42(3):419-30.

63 Wei X, Song H, Yin L, Rizzo MG, Sidhu R, Covey DF, et al. Fatty acid synthesis configures the plasma membrane for inflammation in diabetes. Nature. 2016 Nov;539(7628): 294-8.

64 Tannahill GM, Curtis AM, Adamik J, Palsson-McDermott EM, McGettrick AF, Goel G, et al. Succinate is an inflammatory signal that induces IL-1 $\beta$ through HIF-1 $\alpha$. Nature. 2013 Apr;496(7444):238-42.

65 Vats D, Mukundan L, Odegaard JI, Zhang L, Smith KL, Morel CR, et al. Oxidative metabolism and PGC-1beta attenuate macrophagemediated inflammation. Cell Metab. 2006 Jul; 4(1):13-24.

66 Covarrubias AJ, Aksoylar HI, Yu J, Snyder NW, Worth AJ, Iyer SS, et al. Akt-mTORC1 signaling regulates Acly to integrate metabolic input to control of macrophage activation. eLife. 2016 Feb;5:5.

67 Haschemi A, Kosma P, Gille L, Evans CR, Burant CF, Starkl P, et al. The sedoheptulose kinase CARKL directs macrophage polarization through control of glucose metabolism. Cell Metab. 2012 Jun;15(6):813-26.

68 Corraliza IM, Soler G, Eichmann K, Modolell $M$. Arginase induction by suppressors of nitric oxide synthesis (IL-4, IL-10 and PGE2) in murine bone-marrow-derived macrophages. Biochem Biophys Res Commun. 1995 Jan; 206(2):667-73.

69 Al-Khami AA, Ghonim MA, Del Valle L, Ibba SV, Zheng L, Pyakurel K, et al. Fuelling the mechanisms of asthma: increased fatty acid oxidation in inflammatory immune cells may represent a novel therapeutic target. Clin Exp Allergy. 2017 Sep;47(9):1170-84.

70 Nomura M, Liu J, Rovira II, Gonzalez-Hurtado E, Lee J, Wolfgang MJ, et al. Fatty acid oxidation in macrophage polarization. Nat Immunol. 2016 Mar;17(3):216-7.

71 Divakaruni AS, Hsieh WY, Minarrieta L, Duong TN, Kim KKO, Desousa BR, et al. Etomoxir Inhibits Macrophage Polarization by Disrupting CoA Homeostasis. Cell Metab. 2018 Sep;28(3):490-503.e7.

72 Namgaladze D, Brüne B. Fatty acid oxidation is dispensable for human macrophage IL4-induced polarization. Biochim Biophys Acta. 2014 Sep;1841(9):1329-35.
73 Lavrich KS, Speen AM, Ghio AJ, Bromberg PA, Samet JM, Alexis NE. Macrophages from the upper and lower human respiratory tract are metabolically distinct. Am J Physiol Lung Cell Mol Physiol. 2018 Nov;315(5):L752-64.

74 Mould KJ, Barthel L, Mohning MP, Thomas SM, McCubbrey AL, Danhorn T, et al. Cell Origin Dictates Programming of Resident versus Recruited Macrophages during Acute Lung Injury. Am J Respir Cell Mol Biol. 2017 Sep;57(3):294-306.

75 Guthrie LA, McPhail LC, Henson PM, Johnston RB Jr. Priming of neutrophils for enhanced release of oxygen metabolites by bacterial lipopolysaccharide. Evidence for increased activity of the superoxide-producing enzyme. J Exp Med. 1984 Dec;160(6):165671.

76 Borregaard N, Herlin T. Energy metabolism of human neutrophils during phagocytosis. J Clin Invest. 1982 Sep;70(3):550-7.

77 Porter L, Toepfner N, Bashant KR, Guck J, Ashcroft M, Farahi N, et al. Metabolic Profiling of Human Eosinophils. Front Immunol. 2018 Jun;9:1404.

78 Peachman KK, Lyles DS, Bass DA. Mitochondria in eosinophils: functional role in apoptosis but not respiration. Proc Natl Acad Sci USA. 2001 Feb;98(4):1717-22.

79 Kuo CS, Pavlidis S, Loza M, Baribaud F, Rowe A, Pandis I, et al.; U-BIOPRED Study Group. T-helper cell type 2 (Th2) and non-Th2 molecular phenotypes of asthma using sputum transcriptomics in U-BIOPRED. Eur Respir J. 2017 Feb;49(2):1602135.

80 Barnes PJ, Burney PG, Silverman EK, Celli BR, Vestbo J, Wedzicha JA, et al. Chronic obstructive pulmonary disease. Nat Rev Dis Primers. 2015 Dec;1(1):15076.

81 Barnes PJ. Immunology of asthma and chronic obstructive pulmonary disease. Nat Rev Immunol. 2008 Mar;8(3):183-92.

82 Wedzicha JA, Singh R, Mackay AJ. Acute COPD exacerbations. Clin Chest Med. 2014 Mar;35(1):157-63.

83 Shaykhiev R, Crystal RG. Early events in the pathogenesis of chronic obstructive pulmonary disease. Smoking-induced reprogramming of airway epithelial basal progenitor cells. Ann Am Thorac Soc. 2014 Dec;11 Suppl 5:S252-8.

84 Ahmad T, Sundar IK, Lerner CA, Gerloff J, Tormos AM, Yao H, et al. Impaired mitophagy leads to cigarette smoke stress-induced cellular senescence: implications for chronic obstructive pulmonary disease. FASEB J. 2015 Jul;29(7):2912-29.

85 Ito S, Araya J, Kurita Y, Kobayashi K, Takasaka N, Yoshida M, et al. PARK2-mediated mitophagy is involved in regulation of HBEC senescence in COPD pathogenesis. Autophagy. 2015;11(3):547-59.

86 Hoffmann RF, Zarrintan S, Brandenburg SM, Kol A, de Bruin HG, Jafari S, et al. Prolonged cigarette smoke exposure alters mitochondrial structure and function in airway epithelial cells. Respir Res. 2013 Oct;14(1):97. 
87 Mizumura K, Cloonan SM, Nakahira K, Bhashyam AR, Cervo M, Kitada T, et al. Mitophagy-dependent necroptosis contributes to the pathogenesis of COPD. J Clin Invest. 2014 Sep;124(9):3987-4003.

88 Michaeloudes C, Bhavsar PK, Mumby S, Chung KF, Adcock IM. Dealing with Stress: Defective Metabolic Adaptation in Chronic Obstructive Pulmonary Disease Pathogenesis. Ann Am Thorac Soc. 2017 Nov; 14 (Supplement_5):S374-82.

89 Taylor AE, Finney-Hayward TK, Quint JK, Thomas CM, Tudhope SJ, Wedzicha JA, et al. Defective macrophage phagocytosis of bacteria in COPD. Eur Respir J. 2010 May;35(5): 1039-47.

90 Hodge S, Hodge G, Scicchitano R, Reynolds PN, Holmes M. Alveolar macrophages from subjects with chronic obstructive pulmonary disease are deficient in their ability to phagocytose apoptotic airway epithelial cells. Immunol Cell Biol. 2003 Aug;81(4): 289-96.

91 Bewley MA, Preston JA, Mohasin M, Marriott HM, Budd RC, Swales J, et al. Impaired Mitochondrial Microbicidal Responses in Chronic Obstructive Pulmonary Disease Macrophages. Am J Respir Crit Care Med. 2017 Oct; 196(7):845-55.

92 Belchamber KB, Singh R, Batista CM, Whyte MK, Dockrell DH, Kilty I, et al.; COPD-MAP consortium. Defective bacterial phagocytosis is associated with dysfunctional mitochondria in COPD macrophages. Eur Respir J. 2019 Oct;54(4):1802244.

93 Aridgides DS, Mellinger DL, Armstrong DA, Hazlett HF, Dessaint JA, Hampton TH, et al. Functional and metabolic impairment in cigarette smoke-exposed macrophages is tied to oxidative stress. Sci Rep. 2019 Jul; 9(1):9624.

94 Walton GM, Stockley JA, Griffiths D, Sadhra CS, Purvis T, Sapey E; Can Statins Improve Neutrophil Functions and Clinical Outcomes in COPD. Repurposing Treatments to Enhance Innate Immunity. J Clin Med. 2016 Oct:5(10):E89.

95 Grabcanovic-Musija F, Obermayer A, Stoiber W, Krautgartner WD, Steinbacher P, Winterberg N, et al. Neutrophil extracellular trap (NET) formation characterises stable and exacerbated COPD and correlates with airflow limitation. Respir Res. 2015 May; 16(1):59.

96 Sangaletti S, Tripodo C, Chiodoni C, Guarnotta C, Cappetti B, Casalini P, et al. Neutrophil extracellular traps mediate transfer of cytoplasmic neutrophil antigens to myeloid dendritic cells toward ANCA induction and associated autoimmunity. Blood. 2012 Oct; 120(15):3007-18.

97 Rodríguez-Espinosa O, Rojas-Espinosa O, Moreno-Altamirano MM, López-Villegas EO, Sánchez-García FJ. Metabolic requirements for neutrophil extracellular traps formation. Immunology. 2015 Jun;145(2):21324.
98 Azevedo EP, Rochael NC, Guimarães-Costa AB, de Souza-Vieira TS, Ganilho J, Saraiva EM, et al. A Metabolic Shift toward Pentose Phosphate Pathway Is Necessary for Amyloid Fibril- and Phorbol 12-Myristate 13-Acetate-induced Neutrophil Extracellular Trap (NET) Formation. J Biol Chem. 2015 Sep; 290(36):22174-83.

99 Zhou W, Cao L, Jeffries J, Zhu X, Staiger CJ, Deng Q. Neutrophil-specific knockout demonstrates a role for mitochondria in regulating neutrophil motility in zebrafish. Dis Model Mech. 2018 Mar;11(3):dmm033027.

100 Bao Y, Ledderose C, Graf AF, Brix B, Birsak T, Lee A, et al. mTOR and differential activation of mitochondria orchestrate neutrophil chemotaxis. J Cell Biol. 2015 Sep;210(7):1153-64.

101 Lood C, Blanco LP, Purmalek MM, Carmona-Rivera C, De Ravin SS, Smith CK, et al. Neutrophil extracellular traps enriched in oxidized mitochondrial DNA are interferogenic and contribute to lupus-like disease. Nat Med. 2016 Feb;22(2):146-53.

102 Kurai D, Saraya T, Ishii H, Takizawa H. Virus-induced exacerbations in asthma and COPD. Front Microbiol. 2013 Oct;4:293.

103 Guillot L, Le Goffic R, Bloch S, Escriou N, Akira S, Chignard $M$, et al. Involvement of toll-like receptor 3 in the immune response of lung epithelial cells to double-stranded RNA and influenza A virus. J Biol Chem. 2005 Feb;280(7):5571-80.

104 Groskreutz DJ, Monick MM, Powers LS, Yarovinsky TO, Look DC, Hunninghake GW. Respiratory syncytial virus induces TLR3 protein and protein kinase $\mathrm{R}$, leading to increased double-stranded RNA responsiveness in airway epithelial cells. J Immunol. 2006 Feb;176(3):1733-40.

105 Iwasaki A, Pillai PS. Innate immunity to influenza virus infection. Nat Rev Immunol. 2014 May; 14(5):315-28.

106 Smallwood HS, Duan S, Morfouace M, Rezinciuc S, Shulkin BL, Shelat A, et al. Targeting Metabolic Reprogramming by Influenza Infection for Therapeutic Intervention. Cell Rep. 2017 May;19(8):1640-53.

107 Bajwa G, DeBerardinis RJ, Shao B, Hall B, Farrar JD, Gill MA. Cutting Edge: Critical Role of Glycolysis in Human Plasmacytoid Dendritic Cell Antiviral Responses. J Immunol. 2016 Mar;196(5):2004-9.

108 Gualdoni GA, Mayer KA, Kapsch AM, Kreuzberg K, Puck A, Kienzl P, et al. Rhinovirus induces an anabolic reprogramming in host cell metabolism essential for viral replication. Proc Natl Acad Sci USA. 2018 Jul; 115(30):E7158-65.

109 Thai M, Thaker SK, Feng J, Du Y, Hu H, Ting Wu T, et al. MYC-induced reprogramming of glutamine catabolism supports optimal virus replication. Nat Commun. 2015 Nov;6(1):8873.

110 Kohio HP, Adamson AL. Glycolytic control of vacuolar-type ATPase activity: a mechanism to regulate influenza viral infection. Virology. 2013 Sep;444(1-2):301-9.
111 Liu H, Maruyama H, Masuda T, Honda A, Arai F. The Influence of Virus Infection on the Extracellular pH of the Host Cell Detected on Cell Membrane. Front Microbiol. 2016 Aug; 7:1127.

112 Mallia P, Webber J, Gill SK, Trujillo-Torralbo MB, Calderazzo MA, Finney L, et al. Role of airway glucose in bacterial infections in patients with chronic obstructive pulmonary disease. J Allergy Clin Immunol. 2018 Sep;142(3):815-23.e6.

113 West AP, Shadel GS, Ghosh S. Mitochondria in innate immune responses. Nat Rev Immunol. 2011 Jun;11(6):389-402.

114 Koshiba T. Mitochondrial-mediated antiviral immunity. Biochim Biophys Acta. 2013 Jan;1833(1):225-32.

115 Koshiba T, Yasukawa K, Yanagi Y, Kawabata $\mathrm{S}$. Mitochondrial membrane potential is required for MAVS-mediated antiviral signaling. Sci Signal. 2011 Feb;4(158):ra7.

116 Lee S, Suh GY, Ryter SW, Choi AM. Regulation and Function of the Nucleotide Binding Domain Leucine-Rich Repeat-Containing Receptor, Pyrin Domain-Containing-3 Inflammasome in Lung Disease. Am J Respir Cell Mol Biol. 2016 Feb;54(2):151-60.

117 Xie M, Yu Y, Kang R, Zhu S, Yang L, Zeng L, et al. PKM2-dependent glycolysis promotes NLRP3 and AIM2 inflammasome activation. Nat Commun. 2016 Oct;7(1):13280.

118 Sanman LE, Qian Y, Eisele NA, Ng TM, van der Linden WA, Monack DM, et al. Disruption of glycolytic flux is a signal for inflammasome signaling and pyroptotic cell death. eLife. 2016 Mar;5:e13663.

119 Moon JS, Lee S, Park MA, Siempos II, Haslip $\mathrm{M}$, Lee PJ, et al. UCP2-induced fatty acid synthase promotes NLRP3 inflammasome activation during sepsis. J Clin Invest. 2015 Feb;125(2):665-80.

120 Zhong WJ, Yang HH, Guan XX, Xiong JB, Sun CC, Zhang CY, et al. Inhibition of glycolysis alleviates lipopolysaccharide-induced acute lung injury in a mouse model. J Cell Physiol. 2019 Apr;234(4):4641-54.

121 Li F, Xu M, Wang M, Wang L, Wang H, Zhang $\mathrm{H}$, et al. Roles of mitochondrial ROS and NLRP3 inflammasome in multiple ozone-induced lung inflammation and emphysema. Respir Res. 2018 Nov;19(1):230.

122 Kim SR, Kim DI, Kim SH, Lee H, Lee KS, Cho SH, et al. NLRP3 inflammasome activation by mitochondrial ROS in bronchial epithelial cells is required for allergic inflammation. Cell Death Dis. 2014 Oct;5(10):e1498.

123 Kornberg MD, Bhargava P, Kim PM, Putluri V, Snowman AM, Putluri N, et al. Dimethyl fumarate targets GAPDH and aerobic glycolysis to modulate immunity. Science. 2018 Apr;360(6387):449-53.

124 Michelakis ED, Gurtu V, Webster L, Barnes G, Watson G, Howard L, et al. Inhibition of pyruvate dehydrogenase kinase improves pulmonary arterial hypertension in genetically susceptible patients. Sci Transl Med. 2017 Oct;9(413):eaao4583. 
125 Li J, Li S, Guo J, Li Q, Long J, Ma C, et al. Natural Product Micheliolide (MCL) Irreversibly Activates Pyruvate Kinase M2 and Suppresses Leukemia. J Med Chem. 2018 May;61(9):4155-64.

126 Ricci JE, Chiche J. Metabolic Reprogramming of Non-Hodgkin's B-Cell Lymphomas and Potential Therapeutic Strategies. Front Oncol. 2018 Dec;8:556.

127 Maarsingh H, Dekkers BG, Zuidhof AB, Bos IS, Menzen MH, Klein T, et al. Increased arginase activity contributes to airway remodelling in chronic allergic asthma. Eur Respir J. 2011 Aug;38(2):318-28.

128 Maarsingh $\mathrm{H}$, Zuidhof AB, Bos IS, van Duin $\mathrm{M}$, Boucher JL, Zaagsma J, et al. Arginase inhibition protects against allergen-induced airway obstruction, hyperresponsiveness, and inflammation. Am J Respir Crit Care Med. 2008 Sep;178(6):565-73.
129 Pera T, Zuidhof AB, Smit M, Menzen MH, Klein T, Flik G, et al. Arginase inhibition prevents inflammation and remodeling in a guinea pig model of chronic obstructive pulmonary disease. J Pharmacol Exp Ther. 2014 May;349(2):229-38.

130 Carracedo A, Cantley LC, Pandolfi PP. Cancer metabolism: fatty acid oxidation in the limelight. Nat Rev Cancer. 2013 Apr;13(4): 227-32.

131 Wiegman CH, Michaeloudes C, Haji G, Narang P, Clarke CJ, Russell KE, et al.; COPDMAP. Oxidative stress-induced mitochondrial dysfunction drives inflammation and airway smooth muscle remodeling in patients with chronic obstructive pulmonary disease. J Allergy Clin Immunol. 2015 Sep; 136(3):769-80.

132 Snow BJ, Rolfe FL, Lockhart MM, Frampton CM, O'Sullivan JD, Fung V, et al.; Protect
Study Group. A double-blind, placebo-controlled study to assess the mitochondria-targeted antioxidant MitoQ as a disease-modifying therapy in Parkinson's disease. Moy Disord. 2010 Aug;25(11):1670-4.

133 Gane EJ, Weilert F, Orr DW, Keogh GF, Gibson M, Lockhart MM, et al. The mitochondria-targeted anti-oxidant mitoquinone decreases liver damage in a phase II study of hepatitis C patients. Liver Int. 2010 Aug;30(7):1019-26.

134 Hitchings AW, Lai D, Jones PW, Baker EH; Metformin in COPD Trial Team. Metformin in severe exacerbations of chronic obstructive pulmonary disease: a randomised controlled trial. Thorax. 2016 Jul;71(7):587-93.

135 van der Mijn JC, Panka DJ, Geissler AK, Verheul HM, Mier JW. Novel drugs that target the metabolic reprogramming in renal cell cancer. Cancer Metab. 2016 Jul;4(1):14. 